\title{
A PESQUISA CIENTÍFICA NA SAÚDE: UMA ANÁLISE SOBRE A PARTICIPAÇÃO DE POPULAÇÕES VULNERÁVEIS
}

\author{
Carolina Hespanha Almeida ${ }^{1}$, Rita de Cássia Marques², Dener Carlos Reis ${ }^{3}$, Juliana Machado do Couto e \\ Melo ${ }^{4}$, David Diemert ${ }^{5}$, Maria Flávia Gazzinelli ${ }^{6}$
}

\footnotetext{
${ }^{1}$ Mestre em Enfermagem. Pesquisadora do Laboratório de História e Educação em Saúde da Escola de Enfermagem (EE) da Universidade Federal de Minas Gerais (UFMG). Minas Gerais, Brasil. E-mail: carolinahespanha@yahoo.com.br

${ }^{2}$ Doutora em História. Professor Adjunto da EE/UFMG. Minas Gerais, Brasil. E-mail: rcmarques63@yahoo.com.br

${ }^{3}$ Doutor em Enfermagem. Professor Adjunto da EE/UFMG. Minas Gerais, Brasil. E-mail: denercarlosreis@yahoo.com.br

${ }^{4}$ Mestre em Engenharia de Produção. Pesquisadora do Laboratório de História e Educação em Saúde da Escola da EE/UFMG. Minas Gerais, Brasil. E-mail: julianaemelo@hotmail.com

${ }^{5}$ Mestre em Saúde Pública. Pesquisador do Instituto Sabin. Washington, Unidet States. E-mail: djdiemert@gmail.com

${ }^{6}$ Doutora em Educação. Professor Adjunto da EE/UFMG. Minas Gerais, Brasil. E-mail: flaviagazzinelli@yahoo.com.br
}

RESUMO: Estudo qualitativo com o objetivo de analisar a participação de populações vulneráveis em pesquisas científicas na saúde. Realizado em Americaninhas, Novo Oriente de Minas, Minas Gerais, com nove voluntários dos ensaios clínicos da vacina contra Ancilostomídeos, desenvolvido por um consórcio internacional de instituições de pesquisa. Os dados foram coletados após os testes da vacina, utilizando-se entrevistas semi-estruturadas analisadas por meio da Análise de Conteúdo de Bardin. Os voluntários, em sua maioria, decidiram participar do estudo motivados pela possibilidade de acesso a atendimento em saúde. Conclui-se que a decisão de participar foi marcada pela vulnerabilidade sócio-econômica e psicossocial da população e pela forma como os voluntários constróem simbolicamente esta vulnerabilidade. O estudo aponta a necessidade do preparo da comunidade para participar da pesquisa por meio de uma educação que se traduza em ação, considerando a necessidade de desenvolvimento da autonomia dos sujeitos participantes. DESCRITORES: Pesquisa em saúde. Populações vulneráveis. Autonomia pessoal.

\section{SCIENTIFIC RESEARCH IN HEALTH CARE: AN ANALYSIS ON THE PARTICIPATION OF VULNERABLE POPULATIONS}

\begin{abstract}
This is a qualitative study with the aim to analyze the participation of vulnerable populations in scientific health care research. The study was carried out in Americaninhas, Novo Oriente de Minas, Minas Gerais, Brazil, with nine volunteers enrolled in the clinical trial of a hookworm infection vaccine developed by an international research institution. The data was collected using semi-structured interviews after testing the vaccine and analyzed using Bardin's Content Analysis method. Most volunteers decided to participate in the study motivated by the possibility of receiving access to health care services. We conclude that the decision to participate was influenced by the socio-economic and psychosocial vulnerability of the population and how they symbolically construct this vulnerability. The study points out the need to prepare the community in order to participate in the study through an education translated into action, considering the need for developing autonomy among the participating subjects.
\end{abstract}

DESCRIPTORS: Research in health. Vulnerable population. Personal autonomy.

\section{LA INVESTIGACIÓN CIENTÍFICA EN SALUD: UN ANÁLISIS SOBRE LA PARTICIPACIÓN DE LAS POBLACIONES VULNERABLES}

RESUMEN: Estudio cualitativo con el objetivo de analizar la participación de las poblaciones vulnerables incluidas en investigaciones sobre salud. El estudio se desarrolló en Americaninhas, Novo Oriente de Minas, en Minas Gerais - Brasil, con nueve voluntarios de las pruebas clínicas para experimentación de la vacuna contra Ancilostomídeos, realizado por un consorcio internacional de instituciones de investigación. Los datos fueron recogidos después de las pruebas de la vacuna, mediante entrevistas semiestructuradas analizadas por medio del análisis de contenido de Bardin. La mayoría de los voluntarios decidió participar en el estudio motivados por la posibilidad de acceso a la atención de la salud. Se concluye que la decisión de participar en el estudio fue caracterizada por la vulnerabilidad socioeconómica y psicosocial de esa población y por la forma como esos voluntarios construyen simbólicamente esta vulnerabilidad. El estudio indica la necesidad de preparar a la comunidad a participar en el estudio a través de una educación que se traduzca en una acción dada la necesidad de desarrollo de la autonomía de los sujetos participantes.

DESCRIPTORES: Investigación en salud. Poblaciones vulnerables. Autonomía personal. 


\section{INTRODUÇÃO}

Este artigo traz uma análise sobre a participação de populações vulneráveis inseridas em projetos de pesquisa científica em saúde.

A participação de voluntários em pesquisas em saúde abrange várias questões e é um tema complexo, sobretudo em se tratando de ensaios clínicos - experimentos que envolvem testes de novas tecnologias, drogas terapêuticas e preventivas como as vacinas. Estes indivíduos são submetidos à experimentação científica, expostos a um suposto risco e, provavelmente, não terão a garantia de que serão imediatamente beneficiários dos avanços proporcionados pela investigação.

Diversas regulamentações visam assegurar a integridade e dignidade dos indivíduos que participam de pesquisas biomédicas. Dentre os documentos, destacamos a Declaração de Helsinki, pela sua inegável importância histórica e aceitação mundial, como valor de referência pelas suas diretrizes éticas para pesquisas em seres humanos.

De acordo com a Declaração de Helsinki, para assegurar uma relação ética entre pesquisador e sujeitos da pesquisa, recorre-se ao princípio de garantir que os voluntários estejam cientes das implicações reais e riscos a que serão expostos com a participação na pesquisa em saúde. ${ }^{1} \mathrm{O}$ Termo de Consentimento é o instrumento utilizado para este fim. Pressupõe-se que os indivíduos que o assinam, sejam plenamente capazes de exercer sua vontade, criando sua própria avaliação e crítica que lhes permitam tomar uma decisão segura sobre sua participação ou não no projeto. ${ }^{2}$

A problemática de pesquisas em saúde que envolve a experimentação com seres humanos é campo de análise da Bioética. A consolidação deste campo está ligada às conquistas referentes aos direitos humanos e também aos conflitos morais decorrentes dos rápidos avanços tecnológicos e científicos.

Esta temática é crucial diante de situações de vulnerabilidade dos indivíduos e da evidente necessidade de serem protegidos. $\mathrm{O}$ adjetivo vulnerável encerra uma série de interpretações possíveis. O significado usual de vulnerabilidade leva ao contexto de fragilidade, desproteção, desfavor e, até mesmo, de desamparo ou abandono. Dentro deste contexto, portanto, a vulnerabilidade engloba formas diversas de exclusão ou alijamento de grupos populacionais àqueles fatos ou benefícios que possam estar acontecendo no processo desenvolvimentista mundial.

É consenso entre os pesquisadores que, populações vulneráveis, em função do contexto sócio-cultural dos possíveis voluntários, bem como da linguagem do termo de consentimento, nem sempre compreendem os procedimentos da pesquisa, sua aplicabilidade e quais as consequências de sua participação. ${ }^{3}$

Aliado a isto, existe o contexto sócio-econômico onde se inserem as populações vulneráveis. Neste ponto específico, há a discussão sobre que condições populações extremamente empobrecidas, sem acesso a condições básicas de assistência à saúde, marcadas pela deficiência do sistema educacional e ausência de políticas públicas que respondam às suas necessidades de sobrevivência, teriam para decidir sobre sua participação na pesquisa. ${ }^{4}$

Considerando estes aspectos, observamos que o processo que envolve a tomada de decisões sobre a participação nestes ensaios clínicos inserese em uma questão maior, mais abrangente, que diz respeito à autonomia e cidadania destes sujeitos - uma autonomia para a decisão de participar, conscientes das implicações do estudo. Pois, não obstante os riscos a saúde, nos ensaios clínicos, as pessoas decidem sobre disponibilizar seu corpo para o bem comum, seja por motivações próprias, como ganhos pessoais, ou por considerar tal postura de fundamental importância para a sociedade de uma forma geral. ${ }^{1,5}$

Neste contexto, este estudo tem como objetivo analisar a participação de populações vulneráveis nas pesquisas científicas em saúde e quais aspectos envolvem a decisão de participar de estudos desta natureza.

Embora não tenha sido objeto de grande número de investigações, o preparo da comunidade para a decisão de participar de projetos de pesquisa em saúde vem sendo abordado apenas tangencialmente. ${ }^{7-8}$ Além disso, pouco se sabe sobre quais abordagens pedagógicas seriam mais indicadas para populações envolvidas em pesquisas de saúde, especialmente, populações vulneráveis, com altos índices de analfabetismo.

Nosso estudo se baseia em dados coletados após a realização de um ensaio clínico desenvolvido em uma comunidade rural de Minas Gerais, cujo objetivo é testar uma vacina contra Ancilostomíase, verminose popularmente conhecida como Amarelão.

\section{MÉTODO}

Trata-se de uma pesquisa qualitativa descritiva que se apóia no pressuposto de que os indivíduos pesquisados são sujeitos socialmente 
construídos, relacionam-se com a sociedade através de seu espaço, influenciados, e geradores de influências, por sua cultura, suas histórias, suas crenças e seus valores. ${ }^{9}$

O presente estudo foi desenvolvido em Americaninhas, zona rural do município de Novo Oriente de Minas, nordeste de Minas Gerais. Neste local, estão sendo desenvolvidos os ensaios clínicos de uma nova vacina contra Ancilostomídeos por meio de um consórcio internacional de pesquisadores da Universidade George Washington Medical Center (Estados Unidos), London School of Hygiene and Tropical Medicine (Inglaterra), Queensland Institute of Medical Research (Austrália), Fundação Oswaldo Cruz (Brasil) e Sabin Vaccine Institute (Estados Unidos).

A localidade de Americaninhas tem aproximadamente 4.000 habitantes. A economia local é basicamente constituída pela agricultura familiar e de subsistência, além da criação de animais de pequeno porte para consumo e gado. As moradias são simples, a maioria delas não é servida por rede elétrica. Não há saneamento básico, o que favorece a presença de verminoses na localidade.

Os sujeitos do presente estudo foram nove voluntários dos ensaios clínicos da pesquisa Estudo de Fase I, duplo cego, randomizado e controlado da segurança e imunogenicidade da vacina NA-ASP2 contra Ancilostomídeos em adultos brasileiros previamente infectados (Parecer CONEP 146/2007 de Março de 2007). Foram escolhidos todos os voluntários que participaram do Coorte I da Fase I da pesquisa acima citada. Conforme critério de inclusão na amostra para os testes da vacina, tratam-se de adultos jovens entre 18-49 anos, de ambos os sexos (mulheres não grávidas), que estavam previamente infectados pelo verme Ancilostomídeo e que receberam tratamento supervisionado.

Para o desenvolvimento do nosso estudo seguimos as recomendações da Resolução $N^{\circ}$ 196/1996 do Conselho Nacional de Saúde e o projeto foi aprovado no Comitê de Ética em Pesquisa da Universidade Federal de Minas Gerais - ETIC 362/08. O Termo de Consentimento Livre e Esclarecido foi assinado pelos participantes, depois de esclarecidos sobre o objetivo da pesquisa, garantindo o sigilo das informações e a utilização dos dados gerados apenas para fins científicos.

Para a coleta dos dados, utilizamos entrevistas semi estruturadas que abordaram temas como a decisão e a motivação de participar e a experiência de ser voluntário em pesquisa em saúde. As entrevistas foram gravadas em fitas e transcritas na íntegra para um texto. As falas dos entrevistados apresentam-se na versão original, portanto erros gramaticais e padrões linguísticos e culturais da região podem aparecer no texto. Posteriormente, os dados foram analisados fundamentados na Análise de Conteúdo de Bardin. ${ }^{10}$

Anterior à realização das entrevistas, foi desenvolvida, como parte do preparo de comunidade para os ensaios clínicos, uma intervenção educativa para o processo de decisão de participar ou não como voluntário, nos teste da vacina contra a Ancilostomíase. Esta intervenção incluiu um estudo prévio das representações sociais dos indivíduos sobre a doença, o verme e a vacina. ${ }^{11}$ Fundamentado nestas representações foi elaborado um roteiro de um filme documentário que explorou informações importantes sobre a pesquisa, como é o trabalho dos pesquisadores e por que a vacina está sendo desenvolvida na região, além dos conceitos de experiência, doença, vacina e placebo.

A idéia central do filme era provocar nos participantes uma reflexão acerca dos conceitos apresentados - algo mais, portanto, do que simplesmente conhecer, importando, também, darlhes um significado. Acredita-se que a educação pelo cinema é uma forma de exercitar o pensamento, seja por conceitos, imagens, ou ainda por sensações. Destaca-se que diferente de outros vídeos educativos, comumente utilizados como estratégia de ensino, o filme apresenta por meio de analogias, práticas cotidianas dos habitantes do lugar como plantar e colher mandioca, fazer farinha, produzir doce, queijo, associando esta experiência do cultivo e da culinária local ao trabalho do pesquisador de produzir uma vacina. $O$ filme mostra imagens do trabalho do homem do campo, assim como dos pesquisadores, como uma constante experiência onde se busca, por meio da pesquisa, do controle, alcançar melhores resultados, em grande parte imprevisíveis e de curso indeterminado.

Dessa forma, o filme procurou provocar nos sujeitos um raciocínio analógico entre imagens representativas da pesquisa e elementos de sua experiência. Outro aspecto que diferencia o filme é a participação de pessoas da comunidade como atores e personagens da história. O homem do campo aparece na tela do vídeo e através de uma linguagem que lhe é própria, mostra sua experiência de trabalho, conta o que sabe sobre o projeto de pesquisa ao mesmo tempo que busca tocar os expectadores. 
As sessões de apresentação e discussão do filme foram realizadas com todos os possíveis elegíveis para os ensaios clínicos da vacina, dentre eles os nove voluntários que participaram deste estudo.

\section{RESULTADOS E DISCUSSÃO}

\section{A decisão de participar}

Os indivíduos entrevistados, ao relatar sobre os primeiros contatos com os pesquisadores, expressam seus sentimentos e manifestam sua opinião. Segue a posição de um dos entrevistados: primeiro o pessoal [pesquisadores] foi na minha casa. Aí eles foram e me convidaram para participar da pesquisa. A gente nem sabia ainda direito o que era mas depois disso, na hora eu pensei sem dúvida, eu topo. Não tinha dúvida nenhuma. Não tinha medo. Eu queria participar. Eu tinha muita vontade de participar e eu tinha certeza (A).

A vontade de participar sem ainda conhecer ao certo do que se tratava a pesquisa, sem pensar sobre suas implicações, sinaliza para uma predisposição em inserir-se no estudo. $\mathrm{O}$ entrevistado demonstra a certeza de sua posição e o desejo de participar, que se manifesta sem dúvida, apreensão ou medo.

Estudos sobre a disponibilidade das pessoas em participarem de ensaios clínicos de uma nova vacina, contra HIV/aids, com populações vulneráveis no norte da Tailândia e Índia, evidenciaram que há uma maior predisposição à participação em relação à recusa nestas populações vulneráveis. ${ }^{13}$ Uma possível explicação é que a situação sócio econômica e política, bem como a cultura, os valores e as crenças podem influenciar o desejo e a disponibilidade dos indivíduos para participar. ${ }^{12}$

A decisão em participar pode acontecer motivada por várias razões. Ainda conhecendo pouco ou quase nada sobre o projeto, um dos entrevistados fala em que pautou sua decisão: quando eles foram na minha casa e depois fizeram a reunião $e$ conversaram muito com a gente. Eles perguntavam o que a gente achava da pesquisa. Aí, enquanto eles falavam eu ficava assim imaginando, pensando assim que fosse alguma coisa boa. Eu imaginei que era coisa assim que vale a pena pra saúde da gente (E).

O participante, por conhecer pouco o projeto, construiu uma idéia do que a pesquisa poderia vir a ser, mas tudo no plano especulativo. Vemos emergir aqui que, logo de início, a pesquisa já se apresentava como algo que valeria a pena para a saúde das pessoas, conforme assegura outro entrevistado: [...] eu fiquei sabendo do projeto da vacina e que se tomasse a vacina ia ser bom para a saúde da gente (E).

Conhecer mais sobre o projeto de pesquisa, sua finalidade e implicações não alterou a atitude e postura dos voluntários frente a ele. Mais uma vez observamos que o voluntário não se interroga muito sobre o sentido da sua ação e decide prontamente: eles [pesquisadores] foram na minha casa. Eles conversaram muito com a gente e convidaram pra participar. Medo eu não tive não. Eu sou assim: se eu tenho dúvida eu não me arrisco. Mas eu não tinha dúvida e por isso participei pra gente cuidar do verme (E).

Dois aspectos, aparentemente, favorecem sua decisão positiva: a percepção de que sua participação não representa riscos ou danos pessoais e a motivação de que ao participar da pesquisa estaria cuidando do verme, ou seja, tratando da doença.

A literatura mostra que as percepções dos riscos da pesquisa são questões importantes que orientam os voluntários em sua decisão de participar. $^{12}$

A percepção da possibilidade de acesso a tratamento para a doença norteou a decisão de outros voluntários.

Fizeram as entrevistas perguntando como era o verme. Quem tinha o verme, depois convidou porque ia ter o teste da vacina. Aí cheguei a conclusão e falaram que tinha uma pesquisa pra combater o verme. Eles pediram... convidaram para gente aceitar e a gente aceitou na hora. Para combater o verme (J).

Vieram na minha casa e falaram do projeto. Fez os exames de fezes. Ia ter o projeto da vacina, os testes da vacina sabe, e se eu queria entrar, então eu falei na hora: eu quero. Para a gente tratar do verme (L).

A gente quis participar da pesquisa por causa do tratamento do verme que eles [pesquisadores] fazem com a gente. Por que aqui na região é tudo difícil mesmo. A gente não consegue marcar nada no postinho [Unidade de Saúde] (N).

Nesta última fala, a dificuldade para obtenção de tratamento em condições normais de vida foi o evento decisivo para a participação.

Os voluntários ao revelarem o que pensam sobre a percepção dos seus familiares sobre a pesquisa deixam transparecer que compartilham dos mesmos sentidos por eles atribuídos ao estudo: eles [família] falaram que seria muito bom eu participar. Meu pai falou mesmo: há moço não sei não. Eles falaram assim que era bom porque ai a gente iria ter acompanhamento médico $(\mathrm{N})$. 
Eles [família] falaram que é bom mesmo, porque aí eles [pesquisadores] vão cuidar da saúde da gente. Eles vem na casa da gente e fazem uma visita. Então eles reagiram bem $(\mathrm{E})$.

Eles [família] falaram como é que a gente vai recusar de aceitar isso [projeto vacina]? Com um acompanhamento médico que eles prometeram (J).

Notamos que, para todos os voluntários entrevistados, os ensaios clínicos são procedimentos que traduzem novos modos de cuidar e, portanto, podem refletir em expectativas de beneficios para a saúde. A forma de cuidar dos pesquisadores acompanhamento médico - leva os voluntários a sentirem-se mais amparados pela presença dos médicos nas suas casas. Nestes casos a palavra saúde estaria representada como acesso aos serviços de saúde. O seguinte relato evidencia essa perspectiva.

Com a pesquisa eu senti que iria melhor alguma coisa pra gente. Pensei assim: vai ser bom pra saúde das pessoas daqui. Esse pessoal vindo nas casas da gente, procurando as pessoas, escolhendo as pessoas. Eu achei tudo muito legal. Eu achei que iria ser bom. As coisas estão começando a melhorar por aqui (S).

A pesquisa é vista como algo que vai melhorar as condições de acesso aos serviços de saúde para a comunidade. As ações dos pesquisadores, como as visitas domiciliares e o recrutamento de voluntários são vistos pelo entrevistado como demonstrações de assistência à saúde e possibilidade de benefícios.

Partindo da construção histórica e social em que vivem os indivíduos de áreas vulneráveis, é possível compreender porque existe uma expectativa de esperar benefícios para si próprio, uma vez que residem em áreas onde há dificuldades no acesso à bens e serviços essenciais. A região de Americaninhas, assim como outras áreas rurais, apresenta escassez não apenas de serviços de saúde, mas também saneamento, transporte, educação e outros. Fato este que pode criar nas pessoas uma grande expectativa quando se deparam com as ações dos pesquisadores, já que entendem que na sua região antes não havia esse tipo de serviço. A permanente espera por melhorias justifica-se, pois a ausência de programas de atenção à saúde na zona rural tem repercussões na vida social que vão além do caráter funcional, e cria na população uma rede de dependência que alimenta uma política de assistencialismo sustentada pela carência. ${ }^{13}$

A visita domicilar, para os sujeitos, não representou apenas acesso a saúde mas, veio preencher uma importante lacuna de ordem psi- cossocial destes sujeitos. Por meio do convívio com os pesquisadores, a comunidade estabelece vínculos com a equipe e constrói uma imagem do pesquisador/cientista e do médico: eles [pesquisadores] vieram na minha casa pra falar do projeto. Eles vem muito na minha casa e conversa sobre tudo. Eles são gente muito boa. Eles são muito legais. Tratam a gente assim como a gente é. Já pensou receber gente importante [pesquisadores] assim na sua casa? Eles vêm na casa da gente e faz uma visita. É tão bom isso, receber uma visita dessa na sua casa (L).

O voluntário, ao sentir-se bem tratado pelos pesquisadores, revela, na sua singularidade, que esta sendo respeitado por alguém que, na sua concepção, é muito diferente dele. Neste contexto, sua relação com os pesquisadores atribuí à sua existência uma dignidade própria.

Observamos também, que o entrevistado construiu uma imagem de que os pesquisadores são [...] gente muito boa e importante (L). A imagem do pesquisador como alguém virtuoso vem da percepção de que ele detém um conhecimento científico que muitas vezes é supervalorizado e sobreposto ao conhecimento popular. Trata-se de alguém que fala com autoridade, que tem conhecimento sobre o que fala, o poder do conhecimento e da ciência.

Em outro relato, encontramos a valorização do conhecimento médico: o médico visitando assim direto na casa da gente... eu acho que isso foi muito bom. De vez em quando eles vêm cá fazer uma visita pra gente. Onde é que um médico vem na casa da gente? A gente não sabe nem o que falar pra ele, sabe (L).

$\mathrm{O}$ atendimento médico no domicílio mostrase para este sujeito que convive com a exclusão dos serviços de saúde, como algo que traz satisfação e acarreta até mesmo um constrangimento, evidenciado pela expressão [...] a gente nem sabe o que falar pra ele $(\mathrm{L})$. A percepção de que o conhecimento que detém situa-se em um patamar de legitimidade diferente do conhecimento do médico é evidente. A idéia de que há espaços e interações que definem o que pode ser dito, ou deve ser calado, quem pode dizê-lo e em que circunstâncias, está presente na forma de pensar deste voluntário. Este parece considerar que seu saber é desqualificado frente ao do médico - forma sutil de dominação e controle dos discursos sociais possíveis.

As populações rurais vivem numa constante sensação de se encontrarem no fundo da escala social e da ambígua relação com os médicos e com os serviços de saúde, reforçando-lhes a sensação de incerteza e a prevalência de uma visão nega- 
tiva de si mesmo que reflete e reforça a opressão econômica em que vivem. ${ }^{14}$

A valorização do conhecimento do médico inaugura a relação de confiança entre o voluntário e o médico: eu acredito muito no médico. Assim, o médico examinou a gente. Ele estudou para isso. Ele sabe se a gente pode ou não pode e eu confiei nele (J).

Na relação médico-paciente, normalmente, manifesta-se o sentimento de confiança no profissional qualificado por seus estudos, portanto merecedor dessa confiança. Para o entrevistado, o saber médico está acima de suas dúvidas pois [...] ele estudou pra isso (J). As pesssoas muitas vezes decidem sobre uma conduta médica, sustentadas na confiança que tem no profissional e no conhecimento que acreditam que ele tenha. É uma atitude que está consolidada na imagem do médico como um mito, todo mito é, em si perigoso, pois induz o comportamento das pessoas e inibe o pensamento. ${ }^{15}$

Apesar de destacarmos que a decisão de participar foi motivada pela percepção da ausência de riscos, pela idéia de que a pesquisa poderia combater o verme e a doença, representando cuidados e assistência à saude, não podemos deixar de considerar a expectativa compartilhada de que os testes da vacina poderiam no futuro beneficiar a saúde de outras pessoas. As falas dos voluntários descrevem esta expectativa: eu pensei na hora assim: vai ser bom né! Eu quis [participar] porque até agora foi uma coisa boa. Eles [pesquisadores] trazem muita coisa boa pra gente. Eu pensava assim: se é um teste, assim na frente, daqui um tempo, poderia ser útil pra saúde da gente. Poderia ser bom pra saúde dos outros lugares também. Iria ser bom pra eles [outras pessoas] (S).

Importante assinalar que surge aqui a compreensão de que a pesquisa consiste em testes cujos benefícios serão usufruídos pelas gerações futuras. Igualmente o reconhecimento da importância do estudo para a saúde de uma coletividade: $o$ que mais me motivou, segundo as informações que eu recebi, é que a vacina iria fazer bem para todo o Brasil e para o mundo também (A).

Deparamos aqui com a atitude altruista dos voluntários que remete para a virtude da generosidade, um ato pelo qual o individuo não será contemplado diretamente.

Em síntese, os voluntários no momento em que se defrontam com a possibilidade de participar de um ensaio clínico, algo absolutamente novo e impensado para eles, constróem imagens a seu respeito, sentem-se atraídos pelo que ele pode representar, manifestam suas expectativas, dei- xam transparecer seus valores e crenças, enfim, projetam sobre ele elementos da sua racionalidade e afetividade.

Fundamentados em todos estes dados, podemos afirmar que a educação para o preparo da comunidade realizada por meio do filme/ cinema, não favoreceu aos voluntários a opção ou escolha livre entre as alternativas disponíveis. Dessa forma, há de se pensar nas limitações da educação oferecida. Ao valer-se do cinema, a educação certamente conduziu à compreensão do projeto, embora não tenha oferecido possibilidade para a reflexão sobre as possíveis implicações da decisão tomada.

\section{A decisão de participar: da necessidade à ação livre}

A decisão de participar foi uma experiência marcada pela vulnerabilidade bem como pela forma como esta vulnerabilidade histórica e culturalmente foi construída no imaginário por este agrupamento social. $\mathrm{O}$ fato de a população apresentar necessidades de assistência em vários aspectos, e acreditar muitas vezes poder adquirí-la por meio da sua participação nos ensaios clínicos, favoreceu sobremaneira a sua inserção e permanência no estudo. Admitir isto não significa reconhecer que os sujeitos da pesquisa não compreenderam o Termo de Consentimento no que diz respeito aos possíveis riscos e benefícios oferecidos pelo estudo. Alguns, de fato, não compreenderam o que efetivamente estava sendo proposto - uma pesquisa médica com fins científicos. Por outro lado, os que entenderam o firme propósito da pesquisa, atrelaram sua decisão de participar, ao acesso aos exames clínicos e tratamento. Neste caso, o precário nível sócio-econômico e educacional dos indivíduos, bem como a carência de serviços adequados de saúde, os deixaram levar pelos incentivos a eles prontamente disponibilizados pela pesquisa.

Há populações que historicamente estão situadas às margens da sociedade, sendo pouco favorecidas pelas políticas públicas. Neste contexto, as necessidades básicas dos indivíduos devem ser supridas antes de eles terem a possibilidade de participar do mundo. Quando eles habitam o espaço da necessidade vital, deixam de ser sujeitos de direito, limitados a seu estatuto vital. Apenas dominando a necessidade, os sujeitos não chegam a ser livres, tampouco ingressam na esfera do político, permanecendo na zona designada, como muda e silenciosa. ${ }^{6}$ 
Igualmente, sem conseguir envolver-se com questões que vão além da preocupação com a mera sobrevivência, os indivíduos não criam formas de convivência, interação e comunicação - processos sem os quais não se chega a ação. A ação é uma atividade mais especificamente humana e acontece no coletivo. A coletividade possibilita aos seres humanos constituírem um âmbito de ação, no qual cada um pode se revelar em atos e palavras, o que não faria sentido de modo isolado. ${ }^{13-15}$

A principal condição existencial dos indivíduos é sua potencial liberdade, que se expressa na capacidade dos indivíduos de fazer algo novo. Mas, no âmbito das necessidades, não há liberdade. Somente a libertação das necessidades vitais possibilita uma ação livre. É justamente a capacidade de enxergar além da vida e de agir em relação aos outros, e junto com eles, criando formas de convivência que são, especificamente humana e, que nos distingue da natureza. Dessa forma, reconhece a legitimidade das liberdades individuais, mas liberdade e ação, na sua concepção, são essencialmente coletivas, plurais e políticas. ${ }^{6}$

Apoiados nos conceitos de condição humana e vida política de Hannah Arendt, podemos encontrar uma interessante via de interpretação da atitude dos voluntários que concordaram em participar. As necessidades sócio-econômicas e seus imperativos afastam os sujeitos da palavra livre e da ação autônoma. A passividade frente a proposta de participação na pesquisa, revela a ausência de uma cultura do diálogo, da argumentação, da discordância que define o tom dado ao início das conversações entre pesquisadores e voluntários e sua propensão em participar - ato que parece ser marcado pela irreflexão. ${ }^{6}$

Embora consideremos toda esta argumentação uma importante dimensão da problemática referente à tomada de decisão de populações quanto a sua participação em pesquisas em saúde, temos que ter cuidado e lembrar que tal via de interpretação não a explica em toda sua complexidade. Existem as condições históricas de exclusão e opressão, e, isto é inegável. Vale considerar, entretanto, como estas condições são (re)construídas no imaginário das pessoas. Há processos de subjetivação da vida social dos quais a população de Americaninhas, como qualquer outro agrupamento social, não escapa.

Neste sentido, para a população de Americaninhas, a dificuldade real deixa de ser percebida em seu caráter objetivo e externo e passa a traduzir-se em uma postura niilista, de descrença absoluta com relação a sua possibilidade de ação. É em torno da idéia da vida difícil e de sua impossibilidade frente a ela que os moradores de Americaninhas constróem seus marcos referenciais de identidade, relacionam-se com seus processos saúde e doença e dão respostas aos estímulos intrínsecos e extrínsecos que surgem.

Sintetizando, é no cruzamento das idéias de que a liberdade e a ação se exercitam via diálogo e argumentação e a de que as representações sociais, embora tenham uma longa história, não precisam ser perpetuadas e naturalizadas, emerge um caminho possível para se pensar um trabalho mais ético com as populações vulneráveis inseridas em pesquisas científicas.

\section{CONSIDERAÇÕES FINAIS}

O estudo evidenciou, nesta população, vários aspectos da decisão de participar da pesquisa: os voluntários decidem ser favoráveis ao estudo, motivados pela expectativa de algum benefício imediato para si próprio e para a comunidade. $\mathrm{O}$ tom das entrevistas revelam que, embora o processo educativo realizado, por meio do filme/ cinema, tenha ultrapassado o caráter meramente informativo - denunciado pela literatura como insuficiente para produção de mudança conceitual, de postura e atitude - não foi plenamente suficiente para favorecer às pessoas a tomada de decisões após reflexão. Vale lembrar as limitações deste estudo, pois outros elementos podem ter influenciado tais resultados, pois se trata de uma população pouco escolarizada.

Uma educação para o pensamento e não para o conhecimento é indispensável neste contexto. Constatamos, entretanto, que tal educação não pode prescindir de momentos para o exercício do diálogo, da argumentação, da discussão, do dissenso, da escolha consciente.

Refletindo criticamente sobre a participação de populações vulneráveis em pesquisas e ainda sobre a intervenção realizada pelos pesquisadores dos ensaios clínicos da vacina, há de se pensar em uma educação que se traduza em ação e que ocorra no encontro entre os indivíduos, onde esses confrontariam pontos de vista plurais através da palavra argumentada - a ação. Exatamente aqui, o político e o pedagógico se encontram em uma educação para o preparo de comunidades vulneráveis para as pesquisas científicas que de fato produzam a autonomia dos indivíduos frente a sua participação em pesquisa em saúde. 
Dito de outra forma, a intervenção educativa precisa oferecer momentos para exercitar não só a habilidade de pensar, ou seja, atribuir sentidos, mas a habilidade, peculiar aos homens, de falar e comunicar o que está vendo e sentindo. Ao favorecer encontros entre os indivíduos para pensar sobre seus projetos de vida individuais e sobre o quanto eles se convergem para problemas comuns da comunidade, estaremos contribuindo para o exercício dos processos como a decisão autônoma e a ação.

\section{REFERÊNCIAS}

1. Gambles M. Involving South Asia patients in clinical trial. Health Technol Assess. 2004 Outubro; 8(42):1-109.

2. Hardy E, Bento SF, Osis MJD. Consentimento Informado normalizado pela Resolução 196/96: conhecimento e opinião de pesquisadores brasileiros. Rev Bras Ginecol Obstet. 2002 Jan; 24(1):59-65.

3. Cabral MML, Shindler HC, Abth FGC Regulamentação, conflitos e ética na pesquisa médica em países em desenvovimento. Rev Saúde Pública. 2006 Junho; 40(3):251-7.

4. Capponi S. A biopolítica da população e a experimentação com seres humanos. Ciênc Saúde Colet. 2004 Abr-jun; 9(2):445-55.

5. Ellington L. Decision-Making Issues for Randomized clinical trail participation among Hispanics. Cancer Control. 2003 Sep-Oct; 10(5):98-103.

6. Arendt $\mathrm{H}$. A condição humana. Rio de Janeiro (RJ): Forense Universitária; 2003.
7. Moodley K, Pather M, Myer L. Informed Consent and participant perception of influenza vaccine trials in South Africa. J Med Ethics. 2005 April; 31(1):727-32.

8. Kaljee LM, Pham V, Nguyen DS. Trial participation and vaccine desirability for $\mathrm{Vi}$ - polysaccharide typhoid fever vaccine in Hue City, Vie Nam. Trop Med Int Health. 2006 December; 12(1):25-35.

9. Minayo MCS. O desafio do conhecimento: pesquisa qualitativa em saúde. São Paulo (SP): Editora Hucitec, 2006.

10. Bardin L. Análise de conteúdo. Lisboa (PT): Editora 70; 1977.

11. Penna, CMM. Realidade e imaginário no processo de viver de moradores em um distrito brasileiro. Texto Contexto Enferm. 2007 Jan-Mar; 16(1):12-25.

12. Jenkins RA, Torugsa K, Markowitz LE, Mason CJ, Jamroentana V, Brown AE, Nitayaphan S, et al. Willingness to participate in HIV-1 vaccine trials among young Thai men. Sex Transm Infect. 2000 Jun; (76):386-92.

13. Albuquerque FJB. Psicologia social e formas de vida rural no Brasil. Psic.: Teo e Pesq. 2002 Jan-Abr; 18(1):37-42.

14. Rozemberg B. O saber local e os dilemas relacionados a validação e aplicabilidade do conhecimento científico em áreas rurais. Cad Saúde Pública. 2007 Abril; 23(1):97-105.

15. Alves R. Filosofia da Ciência: introdução ao jogo e as suas regras. $4^{\text {a }}$ ed. São Paulo (SP): Edições Loyola; 2002. 